\title{
Prospective analytical performance evaluation of the QuickNaviTM_COVID19 Ag for asymptomatic individuals
}

Yoshihiko Kiyasu $^{\mathrm{a}, \mathrm{b}^{*}}$, Yuto Takeuchi ${ }^{\mathrm{a}, \mathrm{b}}$, Yusaku Akashib ${ }^{\mathrm{b}, \mathrm{c}}$, Daisuke Kato ${ }^{\mathrm{d}}$, Miwa

Kuwahara $^{\mathrm{d}}$, Shino Muramatsu ${ }^{\mathrm{d}}$, Shigeyuki Notake ${ }^{\mathrm{e}}$, Atsuo Ueda ${ }^{\mathrm{e}}$, Koji Nakamura ${ }^{\mathrm{e}}$, Hiroichi Ishikawa ${ }^{\text {, }}$,Hiromichi Suzukib,g

aDepartment of Infectious Diseases, University of Tsukuba Hospital, 2-1-1 Amakubo, Tsukuba, Ibaraki 305-8576, Japan

${ }^{b}$ Division of Infectious Diseases, Department of Medicine, Tsukuba Medical Center Hospital, 1-3-1 Amakubo Tsukuba, Ibaraki 305-8558, Japan

cAkashi Internal Medicine Clinic, 3-1-63 Asahigaoka, Kashiwara, Osaka 582-0026, Japan

dDenka Co., Ltd. Gosen site, Research \& Development Division, Reagent R\&D

Department, 1-2-2 Minami-hon-cho, Gosen-shi, Niigata 959-1695, Japan

eDepartment of Clinical Laboratory, Tsukuba Medical Center Hospital, 1-3-1 Amakubo, Tsukuba, Ibaraki 305-8558, Japan

fDepartment of Respiratory Medicine, Tsukuba Medical Center Hospital, 1-3-1

Amakubo Tsukuba, Ibaraki 305-8558, Japan

gDepartment of Infectious Diseases, Faculty of Medicine, University of Tsukuba, 1-1-1

Tennodai, Tsukuba, Ibaraki 305-8575, Japan

E-mail addresses of each author: Yoshihiko Kiyasu, Kiyasu-tuk@umin.ac.jp; Yuto

Takeuchi, yuto-takeuchi@umin.ac.jp; Yusaku Akashi, yusaku-akashi@umin.ac.jp;

Daisuke Kato, daisuke-kato@denka.co.jp; Miwa Kuwahara, miwa-

NOTE: This preprint reports new research that has not been certified by peer review and should not be used to guide clinical practice. 
medRxiv preprint doi: https://doi.org/10.1101/2021.04.01.21254813; this version posted April 7, 2021. The copyright holder for this preprint

kuwahara@denka.co.jp; Shino Muramatsu, shino-muramatsu@denka.co.jp; Shigeyuki

Notake,notake@tmch.or.jp; Atsuo Ueda, atsuo.ueda06090727@outlook.jp; Koji

Nakamura, koji-nakamura@tmch.or.jp; Hiroichi Ishikawa, hishikawa@tmch.or.jp;

Hiromichi Suzuki,hsuzuki@md.tsukuba.ac.jp

* Correspondence to:

Yoshihiko Kiyasu

Department of Infectious Diseases, University of Tsukuba Hospital

2-1-1, Amakubo, Tsukuba, Ibaraki 305-8576, Japan

Tel: $+81-29-853-3900$

Fax: $+81-29-853-3479$

E-mail: ykmarines@gmail.com

All authors meet the ICMJE authorship criteria.

Contributor Yoshihiko Kiyasu drafted the manuscript and performed the statistical analyses. Yuto Takeuchi and Yusaku Akashi analyzed the data and revised the manuscript. Hiromichi Suzuki supervised the project. All authors contributed to the writing of the final manuscript. 


\begin{abstract}
Introduction

Antigen testing may help screen for and detect severe acute respiratory syndrome coronavirus 2 (SARS-CoV-2) infections in asymptomatic individuals. However, limited data regarding the diagnostic performance of antigen tests for this group are available.
\end{abstract}

\title{
Methods
}

We used clinical samples to prospectively evaluate the analytical and clinical

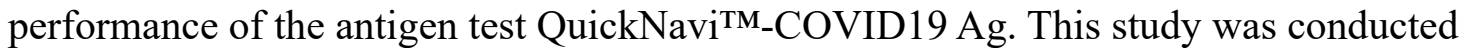
at a PCR center between October 7, 2020 and January 9, 2021. Two nasopharyngeal samples per patient were obtained with flocked swabs; one was used for the antigen test, and the other for real-time reverse transcription PCR (RT-PCR). The diagnostic performance of the antigen test was compared between asymptomatic and symptomatic patients, and the RT-PCR results were used as a reference.

Results

Among the 1,934 collected samples, SARS-CoV-2 was detected by real-time RT-PCR in $188(9.7 \%) ; 76(40.4 \%)$ of these samples were from asymptomatic individuals. Over half of the total samples $(1,073 ; 55.5 \%)$ were obtained from asymptomatic volunteers. The sensitivity of the antigen test was significantly lower for asymptomatic group than for symptomatic patients $(67.1 \%$ vs $89.3 \%, p<0.001)$. The specificity was $100 \%$ for both groups, and no false positives were observed among all 1,934 samples. The median $\mathrm{Ct}$ value for the asymptomatic group was significantly higher than that of the symptomatic group (24 vs $20, p<0.001)$.

\section{Conclusions}

The QuickNaviTM_COVID19 Ag showed a lower sensitivity for asymptomatic group than for symptomatic patients. However, its specificity was consistently high, and no false positives were found in this study.

Keywords: QuickNavi ${ }^{\mathrm{TM}}$ _COVID19 Ag, nasopharyngeal sample, SARS-CoV-2, COVID-19, asymptomatic patient 


\section{Introduction}

Severe acute respiratory syndrome coronavirus 2 (SARS-CoV-2), which causes coronavirus disease 2019 (COVID-19), has overwhelmed healthcare systems globally [1]. The early identification and isolation of patients infected with SARS-CoV-2 are essential for constraining COVID-19 transmission.

Travel restrictions have been enforced worldwide to impede the spread of SARS-CoV2 [2], and many countries have implemented immigration screening measures to minimize the risk of travelers bringing the virus into the country with them [3]; however, the need for resuming domestic and international movement is growing. According to recent data, symptom-based screening, including body-temperature screening, fails to detect a substantial number of SARS-CoV-2-infected patients who have no or mild symptoms [4]. Thus, more accurate screening methods, ideally ones that are convenient and provide rapid results, are desired to detect such individuals.

Although nucleic acid amplification tests (NAATs) are considered highly reliable for detecting SARS-CoV-2, the disadvantages of their finite availability, long turnaround time, and requirement for skilled technicians to perform them have limited their utility for screening purposes [5]. Antigen tests are more accessible point-of-care tests, and they generally take less than an hour to produce results. They can therefore be more beneficial for use in SARS-CoV-2 screening, if their diagnostic performance is sufficient. However, data on the performance of antigen tests in asymptomatic individuals is currently scarce.

Our previous study demonstrated that the antigen test QuickNavi ${ }^{\text {TM}}$-COVID19 Ag (Denka Co., Ltd., Tokyo, Japan) had good performance in the detection of patients with COVID-19, with a sensitivity of $86.7 \%$ (95\% CI: $78.6 \%-92.5 \%)$ and specificity of $100 \%(95 \%$ CI: $99.5 \%-100 \%)$ in 1,186 patients [6]. However, only a few asymptomatic subjects were included in that study, so the diagnostic performance of the QuickNavi ${ }^{\text {TM }}$ COVID19 Ag in asymptomatic individuals could not be thoroughly evaluated.

In the present prospective study, we aimed to evaluate the analytical and clinical performance of the QuickNavi ${ }^{\text {MM}_{-}}$COVID19 Ag in asymptomatic individuals. This study was conducted as an extension study of our previous report [6].

\section{Patients and Methods}


medRxiv preprint doi: https://doi.org/10.1101/2021.04.01.21254813; this version posted April 7, 2021. The copyright holder for this preprint

The details of our study protocol were described previously [6]. Briefly, we prospectively performed this study between October 7, 2020 and January 9, 2021. Sample collection was performed at the PCR center in Tsukuba Medical Center Hospital (TMCH). The enrolled subjects included patients who had been referred from a local public health center or one of 97 primary care facilities and TMCH healthcare workers; clinical information was obtained from each volunteer. All samples from the same patients collected at different timepoints were included in the analysis. The ethics committee of TMCH approved the present study (approval number: 2020-033).

\section{Sample collection and antigen test procedure}

For sample collection, we simultaneously obtained two nasopharyngeal samples: one sample for use in the antigen test, and the other for use in a PCR examination. The antigen test was performed using the QuickNavi ${ }^{\text {TM}}$-COVID19 Ag in accordance with the manufacturers' instructions. The other swab sample was transferred to an in-house microbiology laboratory within an hour of sample collection.

\section{PCR examinations for SARS-CoV-2}

Purification and RNA extraction was performed with magLEAD $6 \mathrm{gC}$ (Precision System Science Co., Ltd., Chiba, Japan) for in-house reverse transcription PCR (RTPCR). The reference real-time RT-PCR of SARS-CoV-2 was performed by using a method developed by the National Institute of Infectious Diseases, Japan [7]. Samples with discrepant results between the reference real-time RT-PCR and in-house RT-PCR were re-evaluated with a GeneXpert ${ }^{\circledR}$ for SARS-CoV-2 (Cepheid Inc., Sunnyvale, CA, USA). The final judgment for the detection of SARS-CoV-2 was based on the GeneXpert ${ }^{\circledR}$ for SARS-CoV-2 result.

\section{Statistical analyses}

The sensitivity and specificity of the QuickNavi ${ }^{\text {TM}}$-COVID19 Ag were calculated using the Clopper and Pearson method, with 95\% confidence intervals (CIs). Ct values were compared between groups using Mann-Whitney $\mathrm{U}$ tests, and $p$-values of $<0.05$ were considered to indicate statistically significant differences. Categorical variables were compared by using a Fisher's exact test. All calculations were conducted using the R 4.0.3 software program (www.r-project.org). 


\section{Results}

During the study period, we evaluated 1,939 nasopharyngeal samples taken from 1,881 volunteers. After excluding the samples collected from subjects for whom symptom data was unavailable $(n=5)$, we were left with 1,934 samples for analysis. Of these 1,934 samples, 1,073 (55.5\%) were from asymptomatic individuals.

SARS-CoV-2 was detected by reference real-time RT-PCR in 187 samples. There was one discordant sample that produced positive results from the in-house RT-PCR assay but negative results from the reference real-time RT-PCR. This sample was deemed positive for SARS-CoV-2 following an additional examination using GeneXpert for SARS-CoV-2 (Ct value of the N2 gene: 42.6). Thus, 188 of 1,934 total samples $(9.7 \%)$ were assessed as positive for SARS-CoV-2. Of the 188 SARS-CoV-2-positive samples, $76(40.4 \%)$ were from asymptomatic individuals.

Sensitivity and specificity of the antigen test in asymptomatic individuals

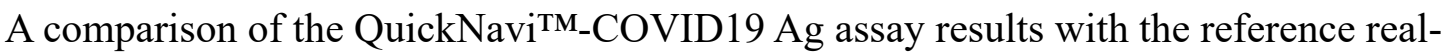
time RT-PCR results for samples from asymptomatic volunteers is summarized in Table 1. The sensitivity and specificity were $67.1 \%$ (95\% CI: 55.4\%-77.5\%) and 100\% (95\% CI: $99.4 \%-100.0 \%$ ), respectively. Of the 25 samples with discordant results between these two assays, all were assessed as negative by the QuickNaviTM_COVID19 Ag assay and assessed as positive by the reference real-time RT-PCR assay (Table 1).

The overall sensitivity and specificity of the antigen test were $80.3 \%$ (95\% CI: $73.9 \%$ $85.7 \%$ ) and 100\% (95\% CI: 99.7\%-100\%), respectively, and no false-positive results were identified among the 1,934 samples. The sensitivity of the QuickNavi ${ }^{\text {TM }}$ COVID19 Ag was $89.3 \%$ (95\% CI: $82.0 \%-94.3 \%)$ for symptomatic patients, which is significantly higher than its sensitivity for asymptomatic individuals $(p<0.001)$. A comparison of test performance between asymptomatic and symptomatic subjects is summarized in Table 2. Additionally, the QuickNavi ${ }^{\text {TM}}$-COVID19 Ag sensitivities stratified by symptom occurrence and $\mathrm{Ct}$ value are shown in Table 3 .

Detailed data of samples with discrepant results between antigen test and real-time RTPCR examinations 
medRxiv preprint doi: https://doi.org/10.1101/2021.04.01.21254813; this version posted April 7, 2021. The copyright holder for this preprint

Among the 37 samples with discrepant results between the antigen test and real-time RT-PCR examinations, 25 were collected from asymptomatic subjects. The N2 gene was detected in all discrepant samples except one from an asymptomatic individual, which yielded positive results from a subsequent GeneXpert for SARS-CoV-2 assay. The N1 gene was not detected in 18 samples (Table 4).

Comparison of the Ct values of samples from symptomatic and asymptomatic subjects The median $\mathrm{Ct}$ values for the $\mathrm{N} 2$ gene of the samples from symptomatic and asymptomatic volunteers were 20 and 24, respectively. The $\mathrm{N} 2$ gene $\mathrm{Ct}$ values for samples from asymptomatic individuals were significantly higher than those for samples from symptomatic patients ( $p<0.001$; Fig. 1). The relationship between $\mathrm{Ct}$ values and days post-symptom onset is shown in Supplementary Figure 1.

\section{Discussion}

Among the 1,073 samples collected from asymptomatic volunteers, the QuickNavi ${ }^{\mathrm{TM}_{-}}$ COVID19 Ag showed a sensitivity of $67.1 \%$ (95\% CI: $55.4 \%-77.5 \%)$ and specificity of 100\% (95\% CI: 99.4\%-100.0\%). The sensitivity of this test for asymptomatic individuals was significantly lower than its sensitivity for symptomatic patients. No false positives were identified on the antigen test results among all 1,934 samples.

Studies of SARS-CoV-2 outbreaks have found that asymptomatic individuals comprise a significant portion of the infected population. [8]. A study of the outbreak on the Japanese cruise ship Diamond Princess reported that 328 out of the 634 confirmed SARS-CoV-2-infected patients were asymptomatic at the time of diagnosis [9]. It has been suggested that infections in asymptomatic individuals play an essential role in the SARS-CoV-2 epidemic [10], and efficient detection of asymptomatic individuals is necessary to control future outbreaks [11]. Because a symptom-based SARS-CoV-2 screening approach is incapable of detecting infected individuals who are asymptomatic, large-scale testing is needed for successful contact tracing. However, it is challenging to perform NAATs on a large scale and at high frequency owing to the limited capacity of laboratories and testing supplies [12]. In this respect, the simplicity and rapidity of antigen testing may make it useful for large-scale COVID-19 screening. There is limited data on the performance of antigen tests in asymptomatic SARS-CoV- 
medRxiv preprint doi: https://doi.org/10.1101/2021.04.01.21254813; this version posted April 7, 2021. The copyright holder for this preprint

2-infected individuals [13]. The current study found that the sensitivity of our antigen test was lower in asymptomatic individuals than in symptomatic patients $(67.1 \% \mathrm{vs}$. 89.3\%). The median viral load may be lower in persons lacking symptoms (Fig. 1), which could explain this finding [14]. A few studies have observed a similar trend of lower antigen test sensitivity in asymptomatic individuals (45.4\% vs. $79.1 \%$ [15], $53.3 \%$ vs. $84.6 \%$ [14]). Nevertheless, the lower sensitivity of COVID-19 antigen tests for asymptomatic individuals does not necessarily negate the utility of these assays for screening purposes. A model study showed that the high frequency and short sample-toresult time of tests might be more important than test accuracy for controlling COVID19 outbreaks via population screening [16]. Furthermore, large-scale screening for SARS-CoV-2 infection demands high specificity to avoid unnecessary further examinations or the application of quarantine measures, which also have social costs [4]. We propose that the QuickNaviTM_COVID19 Ag is a reasonable candidate for use in COVID-19 screening tests, given its very high specificity and lack of false-positive results in 2,796 samples (1,934 nasopharyngeal samples in the present study and 862 anterior nasal samples in our previous study [17]).

Among the group of samples with $\mathrm{Ct}$ values of $<30$, the QuickNavi ${ }^{\text {TM}}-$ COVID19 Ag showed a sensitivity of $>80 \%$ for both symptomatic and asymptomatic subjects. This sensitivity met the performance requirement by the World Health Organization, which suggests that a sensitivity of $\geq 80 \%$ is "acceptable" in samples with $\mathrm{Ct}$ values of $25-30$ [18]. Of the 37 false-negative samples, the majority had a low viral concentration, and only five had $\mathrm{Ct}$ values of $<30$. As indicated in a previous report, patients with low viral shedding have low infectivity [19]. Thus, the risk of overlooking high infectivity patients with COVID-19 in cases when the antigen test provides negative results seems limited. However, asymptomatic individuals who are in the early phase of SARS-CoV-2 infection may later develop symptoms with progressively increasing viral shedding [8]. Therefore, in addition to conducting COVID-19 screenings, symptom follow-up in asymptomatic individuals is essential.

Several limitations associated with the present study warrant mention. First, the results were obtained at a single PCR center during one epidemic season. Whether the same results would be obtained in other regions or during other epidemics requires additional validation. Second, this study did not include patients who had received the vaccine, and the accuracy of the test on SARS-CoV-2-infected patients after vaccination needs to 
be verified in the future. Third, we did not perform a genetic analysis of the detected SARS-CoV-2 variants and did not study the effect of genetic mutation on the antigen test results. Nevertheless, according to manufacturer's information for use (version 4.0), QuickNaviTM_COVID19 Ag reacts with both the SARS-CoV-2 UK variant (VOC202012/01) and the Brazilian variant (501Y.V3, P.1), and the degrees of reaction with these variants are the same as those with the Wuhan strain.

In conclusion, despite showing very high specificity, the QuickNavi ${ }^{\text {TM}}-$ COVID19 Ag has lower sensitivity for detecting SARS-CoV-2 in asymptomatic individuals as compared with its sensitivity in symptomatic patients. Nevertheless, given its high convenience and specificity, this antigen test could be used as a supplementary COVID19 assessment for asymptomatic individuals, as long as the results are interpreted appropriately.

\section{Acknowledgments}

We thank Mrs. Yoko Ueda, Mrs. Mio Matsumoto, Dr. Yumi Hirose, and the staff in the Department of Clinical Laboratory of Tsukuba Medical Center Hospital for their intensive support of this study. We thank all of the medical institutions for providing their patients' clinical information. Mrs. Yoko Ueda and Mrs. Mio Matsumoto significantly contributed to creating the database for this study.

\section{Conflicts of interest}

Denka Co., Ltd. provided fees for research expenses and provided the QuickNavi-COVID19 Ag kits without charge. Hiromichi Suzuki received a lecture fee from Otsuka Pharmaceutical Co., Ltd. regarding this study. Daisuke Kato, Miwa Kuwahara and Shino Muramatsu belong to Denka Co., Ltd., the developer of the QuickNavi ${ }^{\mathrm{TM}}$-COVID19 Ag. 


\section{References}

[1] World Health Organisation. Coronavirus disease (COVID-19) Weekly

Epidemiological Update and Weekly Operational Update.

https://www.who.int/emergencies/diseases/novel-coronavirus-2019/situationreports (accessed March 30, 2021).

[2] Chinazzi M, Davis JT, Ajelli M, Gioannini C, Litvinova M, Merler S, et al. The effect of travel restrictions on the spread of the 2019 novel coronavirus (COVID19) outbreak. Science (80- ) 2020;368:395-400. https://doi.org/10.1126/science.aba9757.

[3] Wilson ME, Chen LH. Re-starting travel in the era of COVID-19: preparing anew. J Travel Med 2020;27:1-5. https://doi.org/10.1093/jtm/taaa108.

[4] Bielecki M, Patel D, Hinkelbein J, Komorowski M, Kester J, Ebrahim S, et al. Air travel and COVID-19 prevention in the pandemic and peri-pandemic period: A narrative review. Travel Med Infect Dis 2021;39:101915. https://doi.org/10.1016/j.tmaid.2020.101915.

[5] Younes N, Al-Sadeq DW, AL-Jighefee H, Younes S, Al-Jamal O, Daas HI, et al. Challenges in laboratory diagnosis of the novel coronavirus SARS-CoV-2. Viruses 2020;12:582. https://doi.org/10.3390/v12060582.

[6] Takeuchi Y, Akashi Y, Kato D, Kuwahara M, Muramatsu S, Ueda A, et al. The evaluation of a newly developed antigen test (QuickNavi ${ }^{\mathrm{TM}}-\mathrm{COVID} 19 \mathrm{Ag}$ ) for SARS-CoV-2: A prospective observational study in Japan. J Infect Chemother 2021. https://doi.org/10.1016/j.jiac.2021.02.029.

[7] Shirato K, Nao N, Katano H, Takayama I, Saito S, Kato F, et al. Development of genetic diagnostic methods for detection for novel coronavirus 2019(nCoV-2019) in Japan. Jpn J Infect Dis 2020;73:304-7. https://doi.org/10.7883/yoken.JJID.2020.061.

[8] Oran DP, Topol EJ. Prevalence of Asymptomatic SARS-CoV-2 Infection : A Narrative Review. Ann Intern Med 2020;173:362-7. https://doi.org/10.7326/M20-3012.

[9] Mizumoto K, Kagaya K, Zarebski A, Chowell G. Estimating the asymptomatic proportion of coronavirus disease 2019 (COVID-19) cases on board the Diamond Princess cruise ship, Yokohama, Japan, 2020. Eurosurveillance 2020;25:1-5. 
https://doi.org/10.2807/1560-7917.ES.2020.25.10.2000180.

[10] Bai Y, Yao L, Wei T, Tian F, Jin D-Y, Chen L, et al. Presumed Asymptomatic Carrier Transmission of COVID-19. JAMA 2020;323:1406.

https://doi.org/10.1001/jama.2020.2565.

[11] Salvagno GL, Gianfilippi G, Bragantini D, Henry BM, Lippi G. Clinical assessment of the Roche SARS-CoV-2 rapid antigen test. Diagnosis 2021. https://doi.org/10.1515/dx-2020-0154.

[12] Shental N, Levy S, Wuvshet V, Skorniakov S, Shalem B, Ottolenghi A, et al. Efficient high-throughput SARS-CoV-2 testing to detect asymptomatic carriers. Sci Adv 2020;6:eabc5961. https://doi.org/10.1126/sciadv.abc5961.

[13] Dinnes J, Deeks JJ, Adriano A, Berhane S, Davenport C, Dittrich S, et al. Rapid, point-of-care antigen and molecular-based tests for diagnosis of SARS-CoV-2 infection. Cochrane Database Syst Rev. Version published: 24 March 2021 https://doi.org/10.1002/14651858.CD013705.pub2.

[14] Okoye NC, Barker AP, Curtis K, Orlandi RR, Snavely EA, Wright C, et al. Performance Characteristics of BinaxNOW COVID-19 Antigen Card for Screening Asymptomatic Individuals in a University Setting. J Clin Microbiol 2021:1-20. https://doi.org/10.1128/jcm.03282-20.

[15] Fenollar F, Bouam A, Ballouche M, Fuster L, Prudent E, Colson P, et al. Evaluation of the panbio COVID-19 rapid antigen detection test device for the screening of patients with COVID-19. J Clin Microbiol 2021;59:2020-2. https://doi.org/10.1128/JCM.02589-20.

[16] Larremore DB, Wilder B, Lester E, Shehata S, Burke JM, Hay JA, et al. Test sensitivity is secondary to frequency and turnaround time for COVID-19 screening. Sci Adv 2020;5393:1-17. https://doi.org/10.1126/sciadv.abd5393.

[17] Takeuchi Y, Akashi Y, Kato D, Kuwahara M, Muramatsu S, Ueda A, et al. Diagnostic Performance and Characteristics of Anterior Nasal Collection for the SARS-CoV-2 Antigen Test: A Prospective Study in Japan. MedRxiv https://doi.org/10.1101/2021.03.03.21252425.

[18] World Health Organization. COVID-19 Target product profiles for priority diagnostics to support response to the COVID-19 pandemic v.1.0 2020:1-38. https://www.who.int/publications/m/item/covid-19-target-product-profiles-forpriority-diagnostics-to-support-response-to-the-covid-19-pandemic-v.0.1 
medRxiv preprint doi: https://doi.org/10.1101/2021.04.01.21254813; this version posted April 7, 2021. The copyright holder for this preprint

(which was not certified by peer review) is the author/funder, who has granted medRxiv a license to display the preprint in perpetuity.

It is made available under a CC-BY-NC-ND 4.0 International license.

(accessed March 30, 2021).

[19] Bullard J, Dust K, Funk D, Strong JE, Alexander D, Garnett L, et al. Predicting Infectious Severe Acute Respiratory Syndrome Coronavirus 2 From Diagnostic Samples. Clin Infect Dis 2020;71:2663-6. https://doi.org/10.1093/cid/ciaa638. 
medRxiv preprint doi: https://doi.org/10.1101/2021.04.01.21254813; this version posted April 7, 2021. The copyright holder for this preprint (which was not certified by peer review) is the author/funder, who has granted medRxiv a license to display the preprint in perpetuity. It is made available under a CC-BY-NC-ND 4.0 International license . 
Table 1. Sensitivity and specificity of QuickNaviTM_COVID19 Ag among asymptomatic individuals

\begin{tabular}{|c|c|c|c|}
\hline \multicolumn{2}{|l|}{ Asymptomatic subjects } & \multicolumn{2}{|c|}{ Real-time RT-PCR } \\
\hline & & Positive & Negative \\
\hline \multirow[b]{2}{*}{ QuickNaviTM_COVID19 Ag } & Positive & 51 & 0 \\
\hline & Negative & 25 & 997 \\
\hline Sensitivity $(\%)$ & & $67.1(55$ & \\
\hline Specificity $(\%)$ & & $100(99$ & \\
\hline Positive predictive value (\%) & & $100(89$ & \\
\hline Negative predictive value (\%) & & $97.6(96$ & \\
\hline
\end{tabular}

RT-PCR, reverse transcription-polymerase chain reaction

Data in parentheses are $95 \%$ confidence intervals. 
medRxiv preprint doi: https://doi.org/10.1101/2021.04.01.21254813; this version posted April 7, 2021. The copyright holder for this preprint

(which was not certified by peer review) is the author/funder, who has granted medRxiv a license to display the preprint in perpetuity.

It is made available under a CC-BY-NC-ND 4.0 International license.

Table 2. Comparison of QuickNaviTM_COVID19 Ag performance between asymptomatic and symptomatic subjects

\begin{tabular}{llll}
\hline & $\begin{array}{l}\text { Asymptomatic subjects } \\
(\mathrm{N}=76)\end{array}$ & $\begin{array}{l}\text { Symptomatic subjects } \\
(\mathrm{N}=112)\end{array}$ & $p$-value \\
\hline Sensitivity (\%) & $67.1(55.4-77.5)$ & $89.3(82.0-94.3)$ & $<0.001$ \\
Specificity (\%) & $100(99.4-100)$ & $100(99.3-100)$ & 1.000 \\
Positive predictive value (\%) & $100(89.7-100)$ & $100(94.6-100)$ & 1.000 \\
Negative predictive value (\%) & $97.6(96.4-98.4)$ & $98.4(97.3-99.2)$ & 0.919 \\
\hline
\end{tabular}

Reverse transcription-polymerase chain reaction was used as the reference.

Data in parentheses are $95 \%$ confidence intervals. 
medRxiv preprint doi: https://doi.org/10.1101/2021.04.01.21254813; this version posted April 7, 2021. The copyright holder for this preprint

\section{Table 3. Antigen test sensitivities stratified by $\mathrm{Ct}$ values}

Ct value (N2 gene) Sensitivity

Total Asymptomatic Symptomatic
$(\mathrm{n}=188)$
$(\mathrm{n}=76)$
$(\mathrm{n}=112)$

Lower than 20

$100(91.7-100) \quad 100(71.3-100)$

$100(89.1-100)$

Between 20-25

$98.2(90.6-100)$

$100(78.1-100)$

$97.1(85.1-99.9)$

Between 25-30

$86.2(68.3-96.1)$

$90.9(58.7-99.8)$

$83.3(58.6-96.4)$

30 or higher

$16.2(6.2-32.0)$

$11.5(2.4-30.2)$

$27.3(6.0-61.0)$

Data in parentheses are $95 \%$ confidence intervals.

$\mathrm{Ct}$, cycle threshold 
Table 4. Detailed data of the 37 samples with discrepant findings between the antigen test and real-time RT-PCR

\begin{tabular}{|c|c|c|c|c|}
\hline \multirow{2}{*}{$\begin{array}{l}\text { Sample } \\
\text { number }\end{array}$} & \multirow[t]{2}{*}{ Symptoms } & \multicolumn{2}{|c|}{$\begin{array}{l}\text { Real-time RT-PCR } \\
\text { (NIID method) }\end{array}$} & \multirow{2}{*}{$\begin{array}{l}\text { GeneXpert }^{\circledR} \\
\text { for SARS-CoV-2 } \\
\mathrm{Ct}(\mathrm{N} 2)\end{array}$} \\
\hline & & $\mathrm{Ct}(\mathrm{N} 1)$ & $\mathrm{Ct}(\mathrm{N} 2)$ & \\
\hline 1 & + & ND & 34 & \\
\hline 2 & + & ND & 40 & \\
\hline 3 & + & 31 & 24 & \\
\hline 4 & + & 35 & 30 & \\
\hline 5 & - & ND & ND & 42.6 \\
\hline 6 & + & 38 & 35 & \\
\hline 7 & - & ND & 36 & \\
\hline 8 & - & ND & 39 & \\
\hline 9 & - & ND & 37 & \\
\hline 10 & - & 37 & 31 & \\
\hline 11 & - & ND & 38 & \\
\hline 12 & + & 36 & 30 & \\
\hline 13 & - & 35 & 30 & \\
\hline 14 & - & 41 & 39 & \\
\hline 15 & - & ND & 34 & \\
\hline 16 & - & ND & 36 & \\
\hline 17 & - & ND & 39 & \\
\hline 18 & + & 31 & 26 & \\
\hline 19 & - & 38 & 33 & \\
\hline 20 & - & 36 & 31 & \\
\hline 21 & - & 35 & 30 & \\
\hline
\end{tabular}


medRxiv preprint doi: https://doi.org/10.1101/2021.04.01.21254813; this version posted April 7, 2021. The copyright holder for this preprint

(which was not certified by peer review) is the author/funder, who has granted medRxiv a license to display the preprint in perpetuity.

It is made available under a CC-BY-NC-ND 4.0 International license .

$+$

26

ND

Ct, cycle threshold; ND, not detected; +, positive; - , negative 
medRxiv preprint doi: https://doi.org/10.1101/2021.04.01.21254813; this version posted April 7, 2021. The copyright holder for this preprint (which was not certified by peer review) is the author/funder, who has granted medRxiv a license to display the preprint in perpetuity. It is made available under a CC-BY-NC-ND 4.0 International license . 
medRxiv preprint doi: https://doi.org/10.1101/2021.04.01.21254813; this version posted April 7, 2021. The copyright holder for this preprint

(which was not certified by peer review) is the author/funder, who has granted medRxiv a license to display the preprint in perpetuity.

It is made available under a CC-BY-NC-ND 4.0 International license .

\section{Figure Legends}

Figure 1. Ct values of samples from symptomatic and asymptomatic subjects. The number next to each box indicates the median $\mathrm{Ct}$ value.

Supplementary Figure 1. Ct values and days post-symptom onset. Blue and red dots

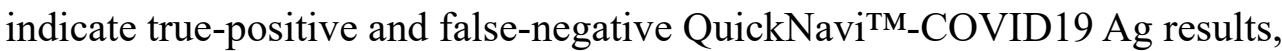
respectively. 
Figure 1

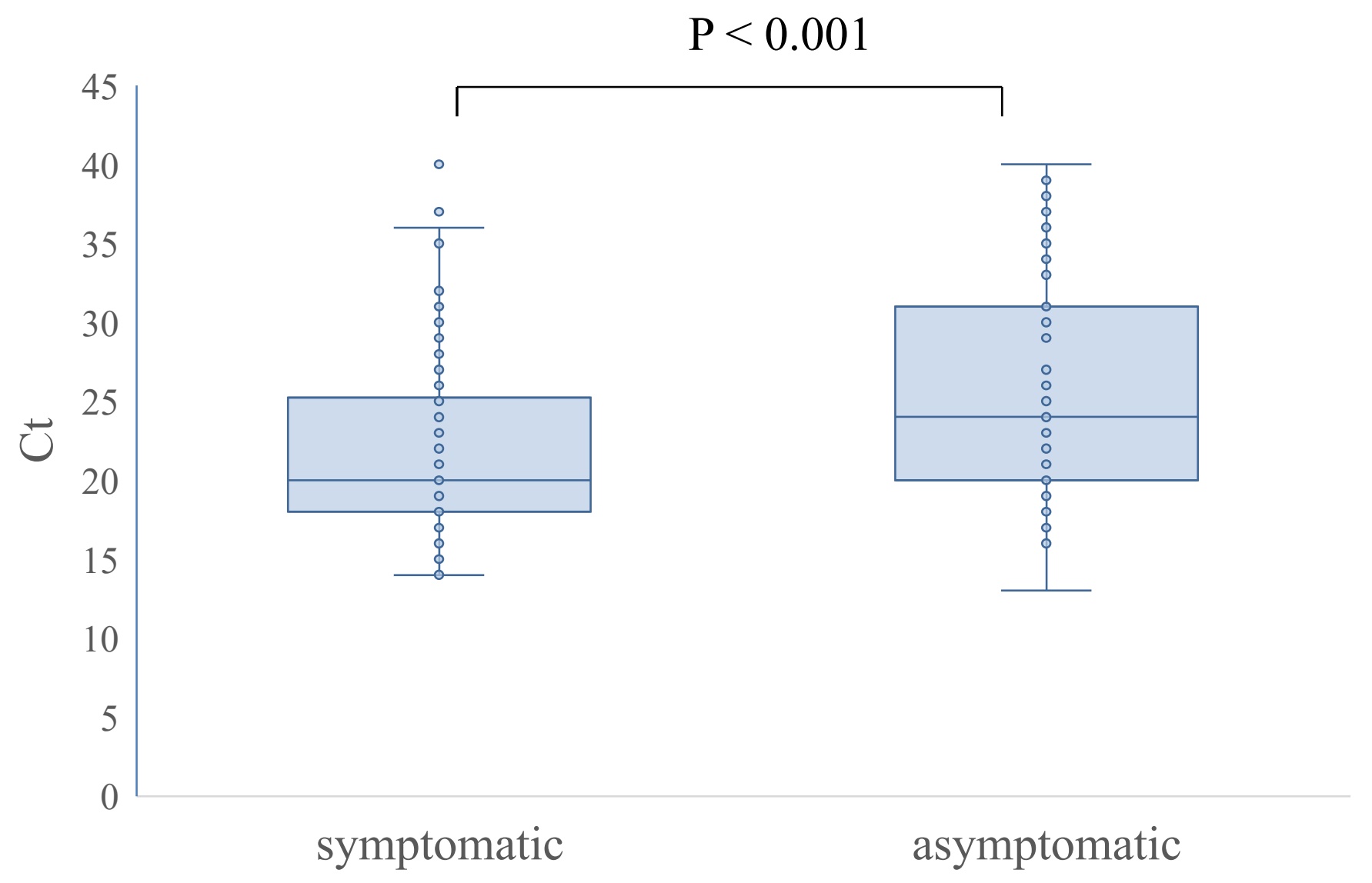

